\title{
Surface Modification of Structural Materials by Low-Energy High-Current Pulsed Electron Beam Treatment
}

\author{
A. V. Panin ${ }^{1, \text { a) }}$, M. S. Kazachenok ${ }^{1, b)}$, O. M. Borodovitsina ${ }^{1,2, c)}$, \\ E. A. Sinyakova, ${ }^{1, \text { d) }}$ Yu. F. Ivanov ${ }^{2,3, e)}$, and M. V. Leontieva-Smirnova ${ }^{4, \text { f) }}$ \\ ${ }^{1}$ Institute of Strength Physics and Materials Science SB RAS, Tomsk, 634055, Russia \\ ${ }^{2}$ National Research Tomsk Polytechnic University, Tomsk, 634050, Russia \\ ${ }^{3}$ Institute of High Current Electronics SB RAS, Tomsk, 634055, Russia \\ ${ }^{4}$ A.A. Bochvar Research Institute of Inorganic Materials, Moscow, 123060, Russia \\ a) Corresponding author: pav@ispms.tsc.ru \\ b) kms@ms.tsc.ru \\ c) oksikom@bk.ru \\ d) mea@ispms.tsc.ru \\ e)yufi55@mail.ru \\ f) chernovv@bochvar.ru
}

\begin{abstract}
Microstructure formation in surface layers of pure titanium and ferritic-martensitic steel subjected to electron beam treatment is studied. It is shown that low energy high-current pulsed electron beam irradiation leads to the martensite structure within the surface layer of pure titanium. Contrary, the columnar ferrite grains grow during solidification of ferritic-martensitic steel. The effect of electron beam energy density on the surface morphology and microstructure of the irradiated metals is demonstrated.
\end{abstract}

\section{INTRODUCTION}

Nowadays, the technology for surface strengthening of structural materials based on low-energy high-current pulsed electron beams (is of great interest [1]. The combination of radiation, thermal and impact-mechanical loading can induce the controllable change in surface morphology, microstructure, element and phase composition of metals and alloys under low-energy high-current pulsed electron beams treatment. As a result, their dynamic strength, wear and corrosion resistances as well as technological properties can be tailored over a wide range by changing treatment parameters $[2-4]$.

Since the low-energy high-current pulsed electron beams irradiation is performed under condition of ultra-high heating and cooling rates, the martensite structure in the melted surface layer is the main factor responsible for surface strengthening of structural materials. The electron irradiation of induced martensitic transformation occurs not only in the surface layer of austenitic steels, but also in different iron alloys, nonferrous metals, etc. [5]. On the contrary, the martensite structure in the surface layer of steels produced by preliminary thermal treatment can be destroyed under subsequent low-energy high-current pulsed electron beams irradiation. As a result, mechanical properties of the steels can become worse [6]. In other words, the effect of the electron-beam treatment is governed not only by its parameters but also by the microstructure of materials. In this study the changes in surface morphology and microstructure of commercially pure titanium and ferritic-martensitic steel RUSFER EK-181 subjected to low-energy high-current pulsed electron beams treatment are demonstrated.

\section{MATERIALS AND RESEARCH METHODS}

The specimens under study were commercially pure titanium (VT1-0 according to the Russian classification) and ferritic-martensitic steel RUSFER-EK-181 (Fe-12Cr-2W-V-Ta-B-C) [7] with the size of $10 \times 10 \times 2 \mathrm{~mm}^{3}$.

International Conference on Physical Mesomechanics of Multilevel Systems 2014 AIP Conf. Proc. 1623, 467-470 (2014); doi: 10.1063/1.4898983

(C) 2014 AIP Publishing LLC 978-0-7354-1260-6/\$30.00 


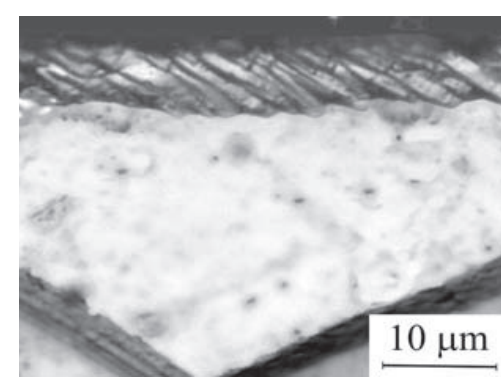

(a)

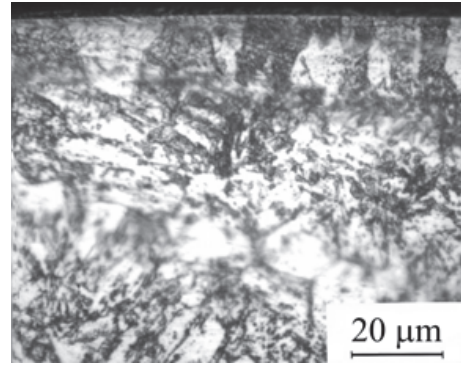

(b)

FIGURE 1. Microstructure of pure titanium (a) and RUSFER-EK-181 steel (b) subjected to the low-energy high-current pulsed electron beams treatment with energy density of 12 (a) and $30 \mathrm{~J} / \mathrm{cm}^{2}$ (b)

Titanium specimens were preliminary annealed for an hour in a vacuum chamber at a temperature of $750^{\circ} \mathrm{C}$. Specimens of the ferritic-martensitic steel had been quenched at $1080^{\circ} \mathrm{C}$ for 1 hour followed by ageing at $720^{\circ} \mathrm{C}$ for 3 hours. Both flat surfaces of the mechanically polished specimens were subjected to low-energy high-current pulsed electron beams treatment using a "SOLO" electron beam irradiation system (IHCE SB RAS, Tomsk). Irradiation was performed in argon atmosphere with a residual pressure of $0.02 \mathrm{~Pa}$. The surface morphology and microstructure of the specimens were examined using a Solver HV atomic force microscope, an Axiovert 40 Mat optical microscope and a LEO EVO 50 scanning electron microscope.

\section{RESULTS AND DISCUSSION}

The basic parameters of the low-energy high-current pulsed electron beams treatment, which variation allow changing the microstructure of metal specimens, are the energy density $W$, the number of pulses and their duration. The low-energy high-current pulsed electron beams treatment is usually carried out by means of a large number of pulses with low energy density $\left(W<1 \mathrm{~J} / \mathrm{cm}^{2}\right)$ or several pulses with energy density of $W=10-30 \mathrm{~J} / \mathrm{cm}^{2}$. In the former case, low-energy high-current pulsed electron beams treatment causes plastic deformation of the metal surface layer that occurs due to thermal stresses and shock waves. In the latter case, the surface layer melts with subsequent fast crystallization. The thickness of the melted surface layer can vary from a few micrometers to a few tens of micrometers (Fig. 1). An increase in the beam energy density $\left(W>40 \mathrm{~J} / \mathrm{cm}^{2}\right)$ and a number of pulses can induce crater eruptions.

The recrystallization process in the melted surface layer of structural materials subjected to the low-energy highcurrent pulsed electron beams treatment is governed by the degree of supercooling of the melt. Indeed, since the underlying bulk material acts as efficient heat sink for the absorbed energy, the melt exists in a metastable supercooled state. According to the numerical calculations [8], the surface layer of pure titanium subjected to the low-energy high-current pulsed electron beams treatment with energy density of $W=10-30 \mathrm{~J} / \mathrm{cm}^{2}$ is characterized by the melt cooling rate as high as $10^{7}-10^{8} \mathrm{~K} / \mathrm{s}$. As a result, small stable crystal nuclei are formed spontaneously in the melt near the liquid-solid interface. Crystal nuclei, as a rule, grow mainly towards the free surface of the specimen that is the reverse direction to the heat sink. Since the grains of different crystallographic orientation are characterized by different growth rates, the preliminary polished surface of metal specimens becomes rough (Figs. 2(a, c) and 3(a)).

After solidification and cooling to room temperature the surface layer of metal specimens is characterized by not only columnar grains, but also different crystalline structure. For example, from the beginning of solidification (1935 K) the grains of $\beta$-Ti are formed in the melted surface layer of pure titanium, subjected to the low-energy high-current pulsed electron beams treatment. Next, when temperature of the recrystallized surface layer drops below $1156 \mathrm{~K}$, polymorphic phase transformations occur in the grains. The distortion of the crystal lattice of $\beta$-Ti grains, induced by residual thermal stresses, as well as quick cooling of the recrystallized surface layer causes the formation of the hexagonal $\alpha^{\prime}$-martensite phase grains, which results from the high-temperature bcc $\beta$-phase grains within the surface-melted layer. Martensite lathes, formed in the surface grains, are also responsible for rough surface of irradiated titanium specimens (Fig. 2(a, d)).

Unlike to titanium and zirconium alloys as well as austenitic steels, martensitic steels subjected to the lowenergy high-current pulsed electron beams treatment can exhibit the reverse transformation from martensite to austenite in a metastable surface-melted layer. Although the cooling is fast, it causes the formation of the ferrite grains, with carbide particles being precipitated at the grain boundary. 


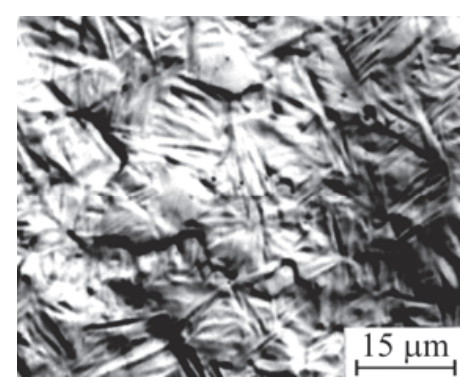

(a)

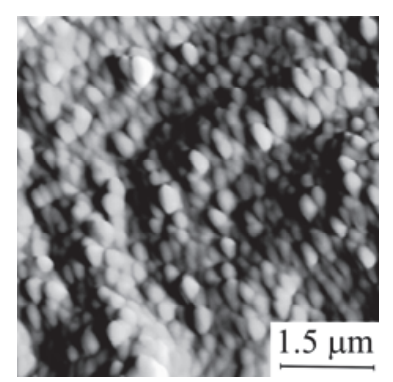

(b)

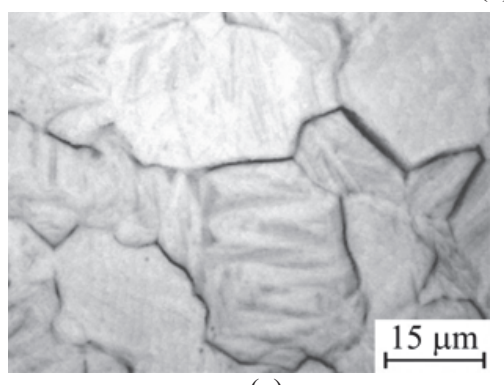

(c)

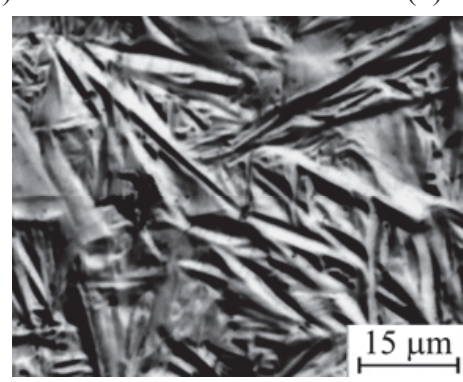

(d)

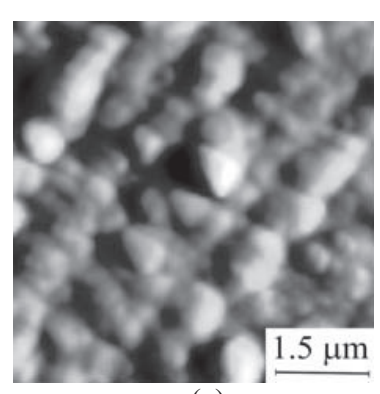

(e)

FIGURE 2. Optical (a, c, d) and AFM-images (b, e) of the titanium specimens subjected to the low-energy high-current pulsed electron beams treatment with energy density of $12(a, b)$ and $24 \mathrm{~J} / \mathrm{cm}^{2}(\mathrm{c}-\mathrm{e})$

Figure 3(b) shows the microstructure of ferritic-martensitic steel RUSFER-EK-181 subjected to quenching and ageing followed by low-energy high-current pulsed electron beams treatment with energy density of $W=30 \mathrm{~J} / \mathrm{cm}^{2}$. There is less evidence for a martensite structure, the columnar ferrite grains are found in the irradiated surface layer (Figs. 1(b) and 3(a, b)).

Along with micron-sized columnar grains, equiaxial grains of nanoscale size are formed on the surface of the irradiated specimens of pure titanium and ferritic-martensitic steel (Figs. 2(b) and 3(c, d)). The fine equiaxial grains are manifested only in the high-resolution AFM-images. The grains of 100-500 nm in diameter appear because of the enhanced release of latent heat of crystallization that decreases the degree of melt supercooling. Note that the fine equiaxial grains can also appear due to concentration overcooling. Since the low-energy high-current pulsed electron beams treatment is performed in argon atmosphere, insoluble impurities, such as oxides and carbides can be formed in the melt, lightening formation of crystal nuclei on the top surface of the specimens.

The presence of martensite lathes inside the fine equiaxial grains formed on the top surface of irradiated titanium specimens is less apparent (Fig. 2(b, d)). This is due to the so-called scale factor that implies the reduction of residual stresses in the fine grains as compared to the coarse columnar grains.

Increasing the energy density of low-energy high-current pulsed electron beams treatment leads to an increase in the surface temperature that results in thickening the melted surface layer. For example, as the energy density increases from 12 to $24 \mathrm{~J} / \mathrm{cm}^{2}$, the thickness of the melted surface layer of titanium specimens increases in the range 6-11 $\mu \mathrm{m}$. The thicker melted layer, in turn, leads to considerable increasing the lifetime of the melt and decreasing melt cooling rate. As a consequence, the degree of supercooling of the melt becomes lower resulting in increasing size of both fine equiaxial grains (compare Fig. 2(b, e) as well as Fig. 3(c, d)) and the subjacent coarse columnar grains. The growth of columnar grains in titanium specimens subjected to low-energy high-current pulsed electron beams treatment manifests itself in the coarser martensite lathes formed within the modified surface layer (compare Fig. 2(a, d)).

Because of crater eruptions, it is possible to increase the thickness of the melted surface layer by means of increasing the number of low-energy high-current pulsed electron beams pulses rather than increasing the energy density. Since the first low-energy high-current pulsed electron beams pulse reduces the heat conduction of a metal specimen due to grain refining, the amount of the heat sinking into the underlying bulk material during the following pulses tends to decrease. Thus, the more intense heating of the surface layer of the specimens subjected to the retreatment, the thicker melt layer would be expected. In other words, every subsequent pulse results in increasing the thickness of the melted surface layer of structural materials. 


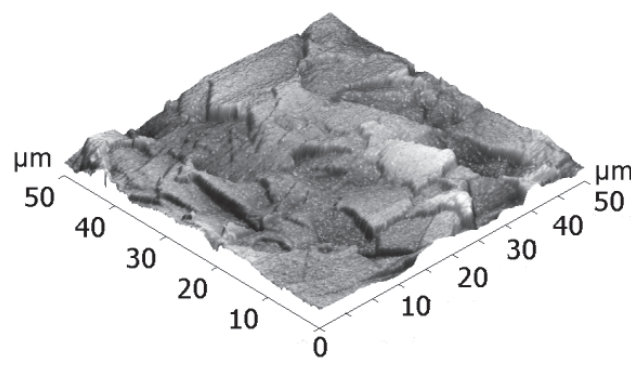

(a)

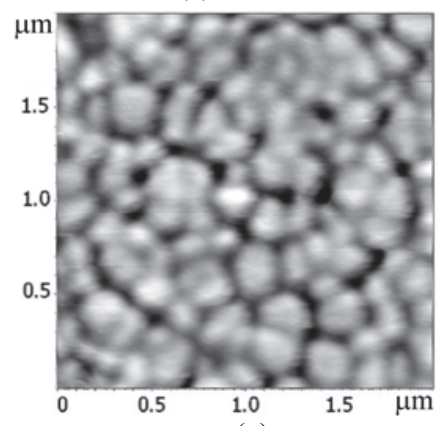

(c)

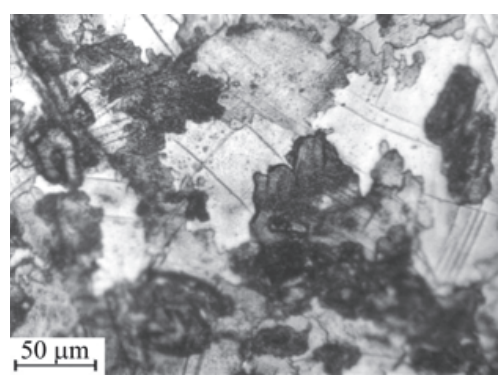

(b)

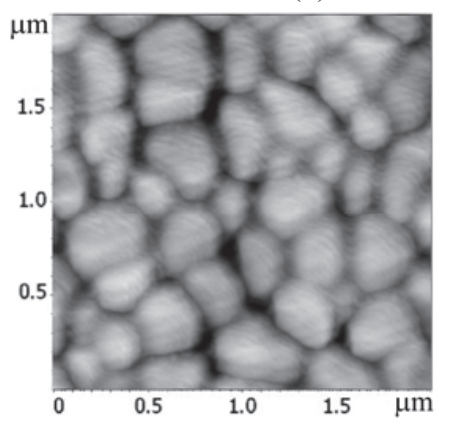

(d)

FIGURE 3. Surface morphology (a, c, d) and microstructure (b) of RUSFER-EK-181 steel subjected to the low-energy highcurrent pulsed electron beams treatment with energy density of $12(\mathrm{a}, \mathrm{b}, \mathrm{c})$ and $30 \mathrm{~J} / \mathrm{cm}^{2}(\mathrm{~d})$

\section{SUMMARY}

Low-energy high-current pulsed electron beams irradiation performed under condition of ultra-high heating and cooling rates dramatically changes the microstructure of commercially pure titanium and ferritic-martensitic steel RUSFER EK-181. It is shown that the $\alpha^{\prime}$-martensite lathes resulted from the high-temperature bcc $\beta$-phase are appeared within the melted surface layer of titanium. Contrary, the columnar ferrite grains grow during solidification of the ferritic-martensitic steel.

Surface morphology study allows revealing the multilayer grain structure that forms within the surface layer of both the metals under the low-energy high-current pulsed electron beams treatment. The modified surface layer of the specimens consists of fine equiaxial grains and subjacent coarse columnar grains. The grain size and, hence, the surface morphology of structural materials subjected to the low-energy high-current pulsed electron beams treatment is governed by the energy density of electron beams. The higher energy density of the low-energy high-current pulsed electron beams treatment, the thicker melted surface layer and the larger equiaxial and subjacent columnar grains. Enlargement of columnar grains in the surface layer of titanium specimens is accompanied by coarsening $\alpha^{\prime}-$ martensite laths within the grains.

The work is supported by Russian Science Foundation (grant No. 14-19-00766).

\section{REFERENCES}

1. Yu. Ivanov, W. Matz, V. Rotshtein, R. Gunzel, and N. Shevchenko, Surf. Coat. Technol. 150, 188 (2002).

2. R. Zenker, Adv. Eng. Mater. 7, 581 (2004).

3. J. X. Zou, K. M. Zhang, S. Z. Hao, C. Dong, and T. Grosdidier, Thin Solid Films 519, 1404 (2010).

4. E. Yun, Y. C. Kim, S. Lee, and N. J. Kim, Metall. Mater. Trans. A 35, 1029 (2004).

5. X. D. Zhang, S. Z. Hao, X. N. Li, C. Dong, and T. Grosdidie, Appl. Surf. Sci. 257, 5899 (2011).

6. L. S. Malinov, E. Ya. Kharlanova, A. V. Zarechenskii, et al., Met. Sci. Heat Treat. 37, 485 (1995).

7. M. V. Leontieva-Smirnova, A. N. Agafonov, G. N. Ermolaev, e. al., Perspekt. Mater. 6, 40 (2006).

8. A. V. Panin, M. S. Kazachenok, O. M. Kretova, et al., Appl. Surf. Sci. 284, 750 (2013). 